\title{
ANALISIS KUALITAS LAYANAN PADA PERUSAHAAN JASA TRAVEL AGENT BERBASIS E-COMMERCE DENGAN METODE E-SERVQUAL DAN QUALITY FUNCTION DEPLOYMENT
}

\author{
Lithrone Laricha $^{1}$, Agung Saryatmo ${ }^{2}$, dan Lita Avilla ${ }^{3}$ \\ ${ }^{1,2}$ Staf Pengajar Program Studi Teknik Industri Universitas Tarumanagara, Jakarta \\ ${ }^{3}$ Mahasiswi Program Studi Teknik Industri Universitas Tarumanagara, Jakarta \\ E-mail: ${ }^{1}$ lithrones@ft.untar.ac.id, ${ }^{2}$ asaryatmo@gmail.com, dan ${ }^{3}$ lita_avilla@hotmail.com
}

\begin{abstract}
Internet media used by individuals and companies for communication and business practice is known as e-commerce which recently has been growing rapidly in Indonesia, one of which is online travel agent. Therefore, this research is aimed to evaluate and improve the service quality of online travel agent company to determine appropriate strategics for achieving competitive advantages and increasing both customer loyalty and long-term profitability. Research data was obtained by reviewing literature and distributing questionnaires to appropriate respondents in Jakarta. The multiple linear regression generated the equation of $Y=0,507+0,412 X_{1}+0,053 X_{2}-0,051 X_{3}+0,048 X_{4}+0,134 X_{5}+0,184 X_{6}-0,038 X_{7}+0,096 X_{8}$. Based on $E-$ ServQual method, negative values obtained from 24-service attributes had not been in accordance with the customer expectation. Researcher obtained four attributes as improvement key-priorities by mapping each attributes into the IPA matrix. Meanwhile, by using Kano model for attributes categorization, researcher was able to derive eight attributes suitable in indifferent category, four attributes in must-be category, and twelve attributes in one-dimensional category. Finally, after integrating the results of E-ServQual and Kano model into QFD, researcher got the five technical responses with the largest percentage which is expected to better fulfill the customer desire and satisfaction.
\end{abstract}

Keywords: Multiple Linear Regression Analysis, E-ServQual, Importance-Performance Analysis, Kano Model, Quality Function Deployment

\begin{abstract}
ABSTRAK
Penggunaan internet oleh perorangan bahkan perusahaan sebagai sarana komunikasi maupun media untuk menjalankan bisnis yang dikenal dengan istilah e-commerce, kini mengalami pertumbuhan pesat di Indonesia, salah satunya yaitu online travel agent. Penelitian ini bertujuan mengevaluasi dan meningkatkan kualitas layanan pada perusahaan jasa online travel agent sehingga didapatkan langkah strategis yang tepat agar tercapainya keunggulan persaingan, meningkatkan loyalitas pelanggan, serta profitabilitas jangka panjang bagi perusahaan. Data penelitian diperoleh melalui studi pustaka dan penyebaran kuesioner kepada responden yang pernah menggunakan layanan online travel agent di Jakarta. Hasil analisis regresi linear berganda menghasilkan persamaan $\mathrm{Y}=0,507+0,412 \mathrm{X}_{1}+0,053 \mathrm{X}_{2}-0,051 \mathrm{X}_{3}+0,048 \mathrm{X}_{4}+0,134 \mathrm{X}_{5}+0,184 \mathrm{X}_{6}-0,038 \mathrm{X}_{7}+0,096 \mathrm{X}_{8}$ Berdasarkan metode E-ServQual, nilai negatif didapatkan pada 24 atribut pelayanan sehingga belum sesuai dengan keinginan pelanggan. Dengan pemetaan tiap atribut kedalam matriks IPA, didapatkan 4 atribut menjadi prioritas utama sebagai perbaikan, dan melalui kategorisasi atribut menggunakan model Kano didapatkan 8 atribut yang masuk ke dalam kategori indifferent, 4 atribut pada kategori must be, dan 12 atribut pada kategori one dimensional. Setelah mengintegrasikan hasil E-ServQual dan model Kano kedalam QFD, terdapat lima respons teknikal yang memperoleh presentase terbesar sehingga diharapkan dengan menerapkan kelimanya mampu memenuhi lebih besar keinginan dan kepuasan pelanggan.
\end{abstract}

Kata kunci: Analisis Regresi Linear Berganda, E-ServQual, Importance-Performance Analysis, Model Kano, Quality Function Deployment. 


\section{PENDAHULUAN}

Pada masa kini, teknologi internet memberikan kontribusi yang besar dalam berbagai aspek kehidupan masyarakat, sehingga menyebabkan perubahan perilaku dan budaya dari yang bersifat tradisional menjadi lebih modern yang salah satunya ditandai dengan digunakannya media internet oleh perorangan bahkan perusahaan untuk menjalankan bisnis atau transaksi perdagangan melalui internet yang dikenal dengan istilah e-commerce sebagai proses jual beli atau pertukaran produk, jasa, dan informasi melalui jaringan komunikasi termasuk internet. Di Indonesia, pangsa pasar e-commerce mengalami pertumbuhan pesat, salah satunya yaitu online travel agent. Dengan banyaknya perusahaan jasa online travel agent berbasis e-commerce yang saat ini sedang berkembang di Indonesia maka diperlukan suatu indikator evaluasi dan penilaian mengenai kualitas pelayanannya berdasarkan aspek kepuasan para pelanggannya sehingga dapat diketahui strategi peningkatan dan perbaikan kualitas layanan yang sesuai untuk diterapkan agar dapat terus bersaing ditengah kemajuan bisnis yang dijalankan secara online di Indonesia serta diperoleh tingkat loyalitas dan kepuasan pelanggan yang tinggi atas pelayanan yang diberikan.

Berdasarkan uraian diatas, tujuan dari penelitian ini adalah menghasilkan nilai koefisien korelasi terbesar dan terkecil yang dihasilkan pada masingmasing dimensi kualitas pelayanan yang ditetapkan, mengetahui performa atribut-atribut kualitas pelayanan perusahaan jasa online travel agent berbasis e-commerce, mengetahui atribut-atribut pelayanan jasa pada online travel agent yang perlu untuk dipertahankan, dikembangkan, atau diperbaiki lebih lanjut, mendapatkan strategi yang baik dan tepat untuk diterapkan dalam meningkatkan kepuasan pelanggan pada penggunaan layanan jasa online travel agent sebagai upaya dalam peningkatan kualitas layanan, dan memperoleh tindakantindakan yang perlu dilakukan oleh perusahaan jasa online travel agent berbasis e-commerce berdasarkan urutan prioritasnya untuk meningkatkan kualitas pelayanan. Batasan masalah yang digunakan dalam penelitian ini adalah responden yang akan diikutsertakan dalam penelitian ini harus sudah pernah menggunakan jasa online travel agent sebelumnya, perusahaan online travel agent yang digunakan sebagai objek penelitian ini adalah hanya yang berbasis dalam negeri, pengumpulan data dilakukan dengan cara menyebar kuesioner kepada responden bagi yang pernah menggunakan jasa travel online di wilayah Jakarta dan dilakukan pada Oktober - November 2016, pengukuran kualitas layanan menggunakan metode E-ServQual dilakukan hanya berdasarkan aspek dari persepsi pelanggan tanpa mempertimbangkan aspek dari faktor internal perusahaan, perusahaan jasa online travel agent yang digunakan sebagai objek penelitian ini dibataskan hanya terhadap tiga perusahaan dan perusahaan yang akan diteliti lebih lanjut adalah yang mendapatkan responden terbanyak dibandingkan dengan dua perusahaan yang lainnya.

\section{TINJAUAN PUSTAKA}

\section{Kualitas Pelayanan}

Kualitas pelayanan dapat didefinisikan sebagai upaya pemenuhan kebutuhan dan keinginan konsumen, serta ketepatan penyampaiannya dalam mengimbangi harapan konsumen [1]. Kualitas pelayanan dapat diketahui dengan membandingkan persepsi konsumen atas pelayanan yang diperoleh dengan pelayanan yang sesungguhnya mereka inginkan terhadap atribut-atribut pelayanan suatu perusahaan. Jika jasa yang diterima atau 
dirasakan sesuai dengan yang diharapkan, maka kualitas pelayanan dipersepsikan baik dan memuaskan. Jika jasa yang diterima melampaui harapan konsumen, maka kualitas pelayanan dipersepsikan sangat baik dan berkualitas. Sebaliknya, jika jasa yang diterima lebih rendah daripada yang diharapkan, maka kualitas pelayanan dipersepsikan buruk.
Uji validitas adalah suatu langkah pengujian yang dilakukan terhadap isi dari suatu instrumen, dengan tujuan untuk mengukur ketepatan instrumen yang digunakan dalam suatu penelitian [2]. Langkah dalam menguji validitas butir pertanyaan pada kuisioner yaitu mencari $r$ hitung (angka korelasi Pearson) dengan rumus sebagai berikut [3]:

\section{Uji Validitas}

$$
\mathrm{r}_{\mathrm{xy}}=\frac{n(\Sigma \mathrm{XY})-(\Sigma \mathrm{X})(\Sigma \mathrm{Y})}{\sqrt{n\left(\Sigma \mathrm{X}^{2}\right)-(\Sigma \mathrm{X})^{2}} \sqrt{n\left(\Sigma \mathrm{Y}^{2}\right)-(\Sigma \mathrm{Y})^{2}}}
$$

Dengan keterangan bahwa $\mathrm{r}$ adalah pearson product moment correlation, $\mathrm{n}$ adalah jumlah sampel, $\mathrm{X}$ adalah skor tiap item, dan $\mathrm{Y}$ adalah skor total.

\section{Uji Reliabilitas}

Uji reliabilitas digunakan untuk mengukur suatu kuisioner yang merupakan indikator dari variabel. Suatu kuisioner dikatakan reliabel apabila jawaban seorang sampel

$$
\alpha=\frac{\mathrm{K}}{\mathrm{K}-1} \cdot \frac{\left[1-\Sigma_{s j}{ }^{2}\right]}{\left[\Sigma_{s x}{ }^{2}\right]}
$$

Dengan keterangan bahwa $\alpha$ adalah koefisien reliabilitas alpha, $\mathrm{K}$ adalah banyaknya item, $\mathrm{Sj}^{2}$ adalah varians skor item, dan $\mathrm{Sx}^{2}$ adalah varians skor total.

\section{Uji Normalitas}

Uji normalitas bertujuan untuk menguji apakah dalam model regresi, variabel bebas dan variabel terikat keduanya memiliki distribusi normal atau tidak. Model regresi yang baik adalah memiliki distribusi data normal atau mendekati normal [5]. Uji normalitas data dilakukan dengan uji Kolmogorov Smirnov dengan ketentuan suatu data dinyatakan

$$
Y=a+b_{1} X_{1}+b_{2} X_{2}+b_{3} X_{3}+\ldots . .+b_{n} X_{n}
$$


Dengan keterangan bahwa $\mathrm{Y}$ adalah variabel dependen; $\mathrm{X}_{1}, \mathrm{X}_{2}, \mathrm{X}_{3}$ hingga $X_{n}$ adalah variabel independen; a merupakan nilai konstanta atau intercept; b adalah koefisien regresi (nilai peningkatan atau penurunan).

\section{Metode E-ServQual}

Kualitas layanan online (eService Quality) adalah tingkat website dapat memfasilitasi secara efisien dan efektif untuk melakukan pembelian, penjualan, dan pengiriman baik produk maupun jasa [7]. E-Service Quality atau yang juga dikenal sebagai E-ServQual merupakan versi baru dari Service Quality (ServQual). E-ServQual dikembangkan untuk mengevaluasi suatu pelayanan yang diberikan pada jaringan Internet. E-ServQual didefinisikan sebagai perluasan dari kemampuan suatu situs untuk memfasilitasi kegiatan belanja, pembelian, dan distribusi secara efektif dan efisien [8].

Dimensi E-ServQual yang digunakan pada penelitian ini terdapat 8 dimensi yang pada masing-masing dimensinya terdapat penjelasan terkait serta beberapa ketentuan atribut. Dimensi $E$ ServQual yang digunakan ini berdasarkan pada 5 dimensi ServQual dan ditambahkan dengan 3 dimensi tambahan lainnya, yaitu website design, reliabillity, responsiveness, security, fulfillment, personalization, information, dan empathy [9].

Evaluasi kualitas jasa menggunakan model E-ServQual mencakup perhitungan perbedaan diantara nilai yang diberikan pelanggan untuk setiap pasang pernyataan berkaitan dengan harapan dan persepsi. Skor E-ServQual untuk setiap pasang pernyataan bagi masing-masing pelanggan dapat dihitung berdasarkan rumus yang dapat dilihat dibawah ini [10]:

E-ServQual Score = Perception Score - Expectation Score

Ketentuan untuk metode $E$ ServQual bila nilai yang diperoleh sama dengan nol $(=0)$ dikatakan "memuaskan", lebih besar dari nol $(>0)$ "sangat memuaskan", sedangkan lebih kecil dari nol $(<0)$ "belum memuaskan".

\section{Importance-Performance Analysis (IPA)}

Metode

Importance-

Performance Analysis (IPA) dibuat untuk mengukur hubungan antara persepsi konsumen dan prioritas peningkatan kualitas produk/ jasa. IPA mempunyai fungsi utama untuk menampilkan informasi berkaitan dengan faktor-faktor pelayanan yang menurut konsumen sangat mempengaruhi kepuasan dan loyalitas mereka, serta faktor-faktor pelayanan yang menurut konsumen perlu ditingkatkan karena kondisi saat ini belum memuaskan. Model matriks IPA dibagi pada 4 kuadran dengan sumbu $\mathrm{X}$ yang menunjukkan nilai kinerja atau persepsi, dan sumbu Y menunjukkan nilai ekspektasi atau kepentingan. Berikut ini merupakan penjelasan 4 kuadran tersebut [11]:

a. Kuadran 1 (concentrate here): atribut yang terletak pada kuadran ini mewakili area kunci yang perlu untuk segera diperbaiki dengan prioritas utama. 
b. Kuadran 2 (keep up the good work): semua atribut yang jatuh ke dalam kuadran ini adalah kekuatan serta pilar dari perusahaan dan bisa menjadi perusahaan tersebut.

c. Kuadran 3 (low priority): atribut yang terletak pada kuadran ini dapat dikatakan tidak terlalu penting dan tidak menimbulkan ancaman bagi perusahaan atau organisasi.

d. Kuadran 4 (possible overkill): atribut yang terletak pada kuadran ini mengartikan bahwa perusahaan terlalu berlebihan dalam memberikan kualitas pelayanannya. Daripada terus berfokus pada atribut yang jatuh di kuadran 4, lebih baik perusahaan mengalokasikan sumber daya terkait dengan faktor-faktor tersebut untuk atribut pada kuadran 1 .

Diagram kartesius untuk ImportancePerformance Analysis (IPA) dapat dilihat pada Gambar 1 berikut ini.

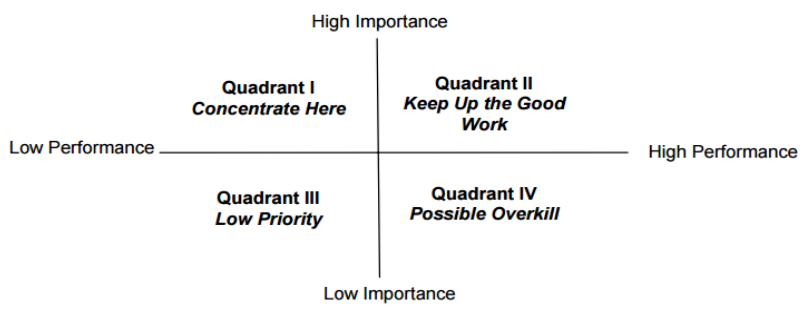

Gambar 1. Diagram Importance-Performance Analysis

\section{Model Kano}

Model Kano merupakan metode yang bertujuan mengkategorikan atribut-atribut produk mapun jasa berdasarkan seberapa baik produk atau jasa tersebut mampu memuaskan kebutuhan pelanggan. Dalam model Kano, dibedakan tiga tipe produk yang diinginkan yang dapat mempengaruhi kepuasan konsumen, yaitu kategori must-be requirements (atribut dasar), one-dimensional requirements (atribut yang diharapkan), dan attractive requirements (atribut yang dapat meningkatkan kepuasan pelanggan). Gambar 2 menggambarkan hubungan antara kepuasan konsumen dengan kinerja dari produk atau jasa untuk ketiga tipe yang telah disebutkan [12]. 


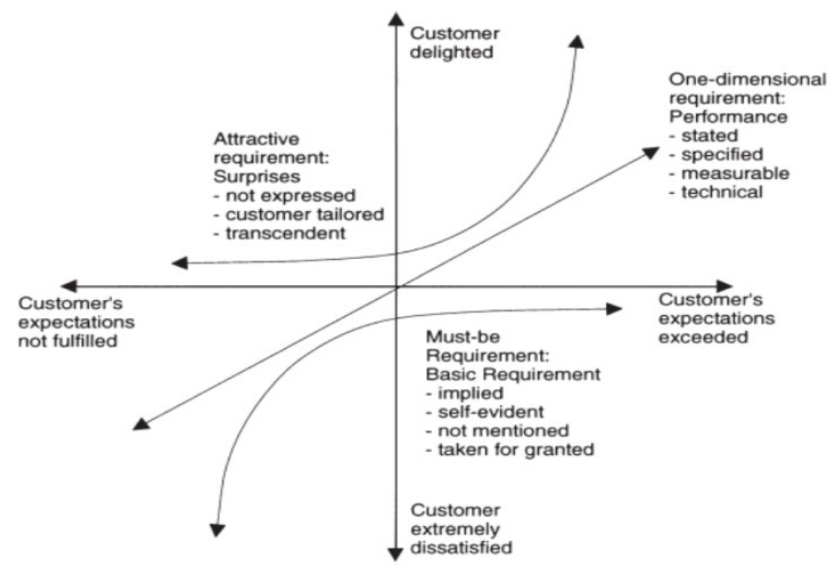

Gambar 2. Diagram Kano

Pengklasifikasian kebutuhan konsumen dalam kuesioner Kano terbagi atas dua macam yaitu pertanyaan fungsional dan disfungsional. Kemudian, hasil dari kedua pernyataan tersebut dapat diklasifikasikan menjadi enam kategori yaitu attractive (A), must-be
$(\mathrm{M})$, one-dimensional $(\mathrm{O})$, indifferent $(\mathrm{I})$, reverse $(\mathrm{R})$, dan questionable (Q). Dengan menggabungkan pertanyaan fungsional dan disfungsional, maka tipe persyaratan suatu produk dapat diklasifikasikan sesuai Tabel 1.

Tabel 1. Tabel Evaluasi Kano

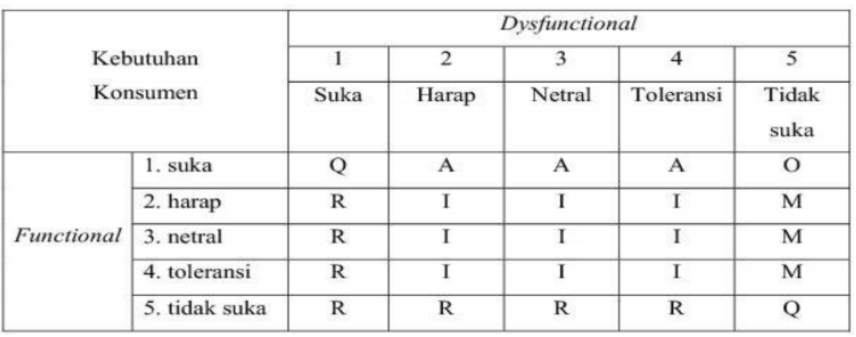

Penentuan kategori Kano tiap atribut dengan menggunakan Blauth's formula menurut yaitu [13]:

a. Jika (one-dimensional + attractive + must-be) $>$ (indifferent + reverse + questionable) maka grade diperoleh dari yang paling maksimum dari (onedimensional, attractive, mustbe).

b. Jika (one-dimensional + attractive + must-be) $<$ (indifferent + reverse + questionable) maka grade diperoleh dari yang paling maksimum dari (indifferent + reverse + questionable).

c. Jika jumlah nilai (onedimensional + attractive + must-be) $=$ (indifferent + reverse + questionable) maka grade diperoleh yang paling maksimum diantara semua kategori kano yaitu (onedimensional, attractive, mustbe, indifferent, reverse, questionable

\section{Quality Function Deployment} (QFD)

QFD merupakan suatu sistem untuk mendesain sebuah produk atau jasa 
yang berdasarkan permintaan pelanggan, dengan melibatkan partisipasi semua fungsi-fungsi yang terdapat dalam organisasi tersebut. Aplikasi QFD dilakukan dalam bentuk matriks besar yang sering disebut sebagai House of Quality (HOQ) yang secara umum terdiri dari dua bagian utama yaitu tabel customer (horizontal matriks) berisi informasi mengenai customer dan tabel teknikal (vertikal matriks) berisi informasi teknis sebagai respon dari keinginan customer. Langkah pembuatan HOQ terbagi atas tiga bagian besar yaitu mengidentifikasi suara pelanggan, membuat matrik kebutuhan teknikal, dan menentukan target. Gambar 3 menunjukkan bentuk matriks umum dari House of Quality [14].

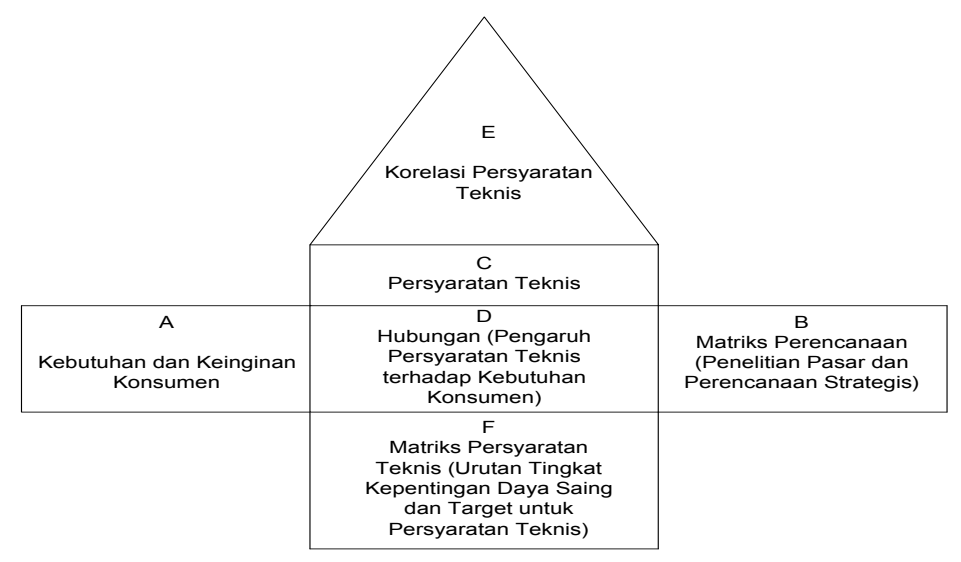

Gambar 3. Bentuk Matriks Umum House of Quality

METODOLOGI PENELITIAN

Metodologi penelitian merupakan proses yang harus dilakukan secara bertahap. Setiap tahapan penelitian harus dilakukan secara rinci dan jelas sehingga penelitian memiliki arah yang jelas, bersifat sistematis, logis, dan empiris yaitu dapat diuji kebenarannya [15]. Sumber data yang digunakan dalam penelitian ini adalah sumber primer yang diperoleh langsung oleh peneliti dari tangan pertama. Sumber primer yang digunakan dalam penelitian ini adalah data hasil pengisian kuesioner oleh 219 responden yaitu para pelanggan website jasa layanan 3 perusahaan online travel agent di Jakarta. Teknik pengumpulan data yang digunakan adalah dengan menggunakan kuesioner yang pengisiannya berdasarkan skala likert. Teknik pengambilan sampel dilakukan dengan teknik purposive sampling. Dalam proses pengolahan data lebih lanjut, ditetapkan bahwa perusahaan jasa online travel agent untuk diteliti lebih lanjut adalah yang mendapatkan responden terbanyak dibandingkan dengan dua perusahaan lainnya. 
Kuesioner yang digunakan dalam penelitian ini terbagi atas 3 bagian yaitu untuk data karakteristik responden, metode E-ServQual, dan model Kano. Untuk kuesioner $E$ ServQual berisi 24 pernyataan yang merupakan representasi dari 8 dimensi kualitas jasa layanan online, meliputi website design, reliability, responsiveness, security, fulfillment, personalization, information, dan empathy yang keterangannya dapat dilihat pada Lampiran 1. Pada kuesioner Kano terdapat dua jenis yaitu pertanyaan functional dan dysfunctional, yang keduanya juga berisi 24 pertanyaan berdasarkan atribut E-ServQual yang telah ditetapkan.

Metode yang akan digunakan pada penelitian ini adalah analisis regresi linear berganda, perhitungan gap score berdasarkan dimensi pada E-ServQual, pemetaan diagram kartesius menggunakan prinsip Importance-Performance Analysis, kategorisasi menggunakan model Kano yang kemudian hasilnya dari secara keseluruhan akan digunakan sebagai prioritas dalam peningkatan kualitas layanan pada perusahaan jasa online travel agent berbasis $e$ commerce

\section{HASIL DAN PEMBAHASAN}

Berdasarkan data karakteristik responden yang terkumpul, presentase pelanggan online travel agent PT. A $82,19 \%$, PT. B 13,69\%, dan PT. C 4,12\%. Untuk jenis layanan yang sering diakses adalah pemesanan tiket pesawat dengan presentase $44,29 \%$, pemesanan tiket kereta api 18,26\%, dan pemesanan kamar hotel 37,45\%. Frekuensi pelangganan layanan online travel agent terbesar yaitu 30,59\% untuk 57 kali, 26,48\% untuk 3-5 kali, lebih dari 7 kali sebesar 24,21\%, dan frekuensi 1-2 kali sebesar 18,72\%. Hasil rekapitulasi data karakteristik responden pada bagian 'online travel agent yang paling sering digunakan' menunjukkan bahwa PT. A mendapatkan responden terbanyak, sehingga hasil kuesioner yang akan terus diolah lebih lanjut adalah milik PT. A.

\section{Hasil Uji Validitas}

Pada penelitian ini, uji validitas dilakukan dengan menggunakan program SPSS 23. Teknik pengujian yang digunakan adalah menggunakan korelasi Bivariate Pearson (Produk Momen Pearson) yang mengkorelasikan masingmasing skor item dengan skor total. Berdasarkan analisis yang telah dilakukan, maka didapatkan seluruh 24 pernyataan dalam kuesioner dengan banyaknya jumlah responden sebanyak 180 orang adalah valid, dengan pertimbangan bahwa setiap nilai korelasi yang terhitung lebih besar dari nilai $\mathrm{R}$ tabel dengan angka 0,191 .

\section{Hasil Uji Reliabilitas}

\begin{tabular}{lcr}
\multicolumn{1}{c}{ Pada } & penelitian ini, uji \\
reliabilitas & dilakukan & dengan \\
menggunakan & program & SPSS \\
23. Teknik & pengujian & yang
\end{tabular}
digunakan adalah menggunakan persamaan Cronbach's Alpha. Berdasarkan analisis yang telah dilakukan, maka didapatkan seluruh 24 pernyataan dalam kuesioner dengan banyaknya jumlah responden sebanyak 180 orang adalah reliable karena melebihi ketentuan nilai Alpha yaitu 0,70, dengan didapatkan nilai Cronbach's Alpha sebesar 0,966 
untuk kuesioner bagian ekspektasi pelanggan dan 0,952 untuk kuesioner bagian persepsi pelanggan.

\section{Hasil Uji Normalitas}

Uji normalitas dilakukan menggunakan program SPSS 23 dan menggunakan teknik Kolmogorov Smirnov. Berdasarkan analisis yang telah dilakukan, maka didapatkan nilai sebesar 0,104 untuk dimensi variabel X1, 0,119 untuk dimensi variabel $\mathrm{X} 2,0,154$ untuk dimensi variabel X3, 0,164 untuk dimensi variabel $\mathrm{X} 4,0,181$ untuk dimensi variabel X5, 0,239 untuk dimensi variabel X6, 0,248 untuk dimensi variabel $X 7,0,159$ untuk dimensi variabel $\mathrm{X} 8$, dan 0,080 untuk variabel $Y$. Dengan didapatkannya nilai-nilai tersebut, maka data berdistribusi normal karena nilai signifikansi diatas 0,05 berarti data yang akan diuji tidak mempunyai perbedaan yang signifikan dengan data normal baku.

\section{Analisis Regresi Linear Berganda}

Persamaan regresi linear berganda didapatkan melalui perhitungan menggunakan software SPSS 23 dan menghasilkan persamaan regresi linear berganda sebagai berikut:

$\mathrm{Y}=0,507+0,412 \mathrm{X}_{1}+0,053 \mathrm{X}_{2}-$ $0,051 \mathrm{X}_{3}+0,048 \mathrm{X}_{4}+0,134 \mathrm{X}_{5}+$ $0,184 \mathrm{X}_{6}-0,038 \mathrm{X}_{7}+0,096 \mathrm{X}_{8}$ Interpretasi dari persamaan regresi linear berganda yang dihasilkan yaitu sebagai berikut:

a. X1 (website design) terhadap kepuasan pelanggan $(\mathrm{Y})$

Nilai koefisien regresi untuk variabel X1 sebesar 0,412. Hal ini berarti bahwa setiap kenaikan X1 satu satuan maka variabel $\mathrm{Y}$ akan naik sebesar 0,412 dengan asumsi bahwa variabel bebas yang lain dari model regresi adalah tetap atau konstan.

b. X2 (reliability) terhadap kepuasan pelanggan $(\mathrm{Y})$

Nilai koefisien regresi untuk variabel X2 sebesar 0,053. Hal ini berarti bahwa setiap kenaikan X2 satu satuan maka variabel $\mathrm{Y}$ akan naik sebesar 0,053 dengan asumsi bahwa variabel bebas yang lain dari model regresi adalah tetap atau konstan.

c. X3 (responsiveness) terhadap kepuasan pelanggan (Y)

Nilai koefisien regresi untuk variabel X3 sebesar -0,051. Hal ini berarti bahwa setiap kenaikan X3 satu satuan maka variabel $\mathrm{Y}$ akan turun sebesar -0,051 dengan asumsi bahwa variabel bebas yang lain dari model regresi adalah tetap atau konstan.

d. X4 (security) terhadap kepuasan pelanggan (Y)

Nilai koefisien regresi untuk variabel X4 sebesar 0,048. Hal ini berarti bahwa setiap kenaikan X4 satu satuan maka variabel $\mathrm{Y}$ akan naik sebesar 0,048 dengan asumsi bahwa variabel bebas yang lain dari model regresi adalah tetap atau konstan.

e. X5 (fulfillment) terhadap kepuasan pelanggan $(\mathrm{Y})$

Nilai koefisien regresi untuk variabel X5 sebesar 0,134. Hal ini berarti bahwa setiap kenaikan X5 satu satuan maka variabel $\mathrm{Y}$ akan naik sebesar 0,134 dengan asumsi 
bahwa variabel bebas yang lain dari model regresi adalah tetap atau konstan.

f. X6 (personalization) terhadap kepuasan pelanggan (Y)

Nilai koefisien regresi untuk variabel X6 sebesar 0,184. Hal ini berarti bahwa setiap kenaikan X6 satu satuan maka variabel $\mathrm{Y}$ akan naik sebesar 0,184 dengan asumsi bahwa variabel bebas yang lain dari model regresi adalah tetap atau konstan.

g. X7 (information) terhadap kepuasan pelanggan $(\mathrm{Y})$

Nilai koefisien regresi untuk variabel X7 sebesar $-0,038$.

Hal ini berarti bahwa setiap kenaikan X7 satu satuan maka variabel $\mathrm{Y}$ akan turun sebesar -0,038 dengan asumsi bahwa variabel bebas yang lain dari model regresi adalah tetap atau konstan.

h. X8 (empathy) terhadap kepuasan pelanggan $(\mathrm{Y})$

Nilai koefisien regresi untuk variabel X8 sebesar 0,096.

Hal ini berarti bahwa setiap kenaikan X8 satu satuan maka variabel $\mathrm{Y}$ akan naik sebesar 0,096 dengan asumsi bahwa variabel bebas yang lain dari model regresi adalah tetap atau konstan.

i. a (intercept) terhadap kepuasan pelanggan (Y)

Konstanta atau intercept sebesar $\quad 0,507 \quad$ secara matematis menyatakan bahwa jika semua variabel bebas memiliki nilai 0 maka nilai variabel terikat adalah 0,507.

\section{Nilai Kualitas Pelayanan dengan E-ServQual}

Berdasarkan

analisis

perhitungan yang telah dilakukan untuk setiap atribut pelayanan yang dapat dilihat pada Lampiran 2, didapatkan hasil bahwa kualitas pelayanan oleh perusahaan online travel agent PT. A secara keseluruhan belum sesuai dengan keinginan pelanggan karena tidak terdapat atribut yang menunjukkan bahwa ekspektasi lebih kecil dari persepsi, atau dengan kata lain belum memuaskan karena masih didapatkan nilai kesenjangan yang negatif untuk 24 atribut pelayanan terkait. Dengan demikian dapat dikatakan bahwa seluruh atribut-atribut tersebut perlu mendapatkan perhatian untuk proses perbaikan dan ditingkatkan kualitasnya agar dapat memuaskan kebutuhan pelanggan.

Untuk analisis perhitungan yang telah dilakukan untuk 8 dimensi secara keseluruhan yang dapat dilihat pada Tabel 2, semua nilai gap yang dihasilkan bernilai negatif pada setiap dimensi dengan nilai gap tertinggi yaitu pada dimensi security sebesar -0,24 dan yang terendah pada dimensi personalization sebesar 0,06. Jika dilihat berdasarkan perspektif dimensi, maka perusahaan perlu menitikberatkan prioritas perbaikan yang utama adalah pada dimensi secur 
Tabel 2. Rata-Rata E-ServQual Score Tiap Dimensi

\begin{tabular}{|c|c|c|c|c|}
\hline No & Dimensi & Nilai Persepsi & Nilai Ekspektasi & E-ServQual Score \\
\hline 1 & Website Design & 4,09 & 4,21 & $-0,12$ \\
\hline 2 & Reliability & 4,04 & 4,21 & $-0,17$ \\
\hline 3 & Responsiveness & 3,91 & 4,14 & $-0,23$ \\
\hline 4 & Security & 4,08 & 4,32 & $-0,24$ \\
\hline 5 & Fulfillment & 4,14 & 4,32 & $-0,18$ \\
\hline 6 & Personalization & 4,15 & 4,21 & $-0,06$ \\
\hline 7 & Information & 4,07 & 4,24 & $-0,17$ \\
\hline 8 & Empathy & 4,03 & 4,21 & $-0,18$ \\
\hline \multicolumn{5}{|c|}{ Rata-Rata } \\
\end{tabular}

\section{Matriks \\ Performance Analysis (IPA)}

Hasil pengolahan data yang telah dilakukan menggunakan metode $E$ ServQual dapat dipetakan ke dalam diagram kartesius berdasarkan prinsip Importance-Performance Analysis untuk mengidentifikasi kekuatan dan kelemahan yang dimiliki suatu perusahaan sebagaimana yang dapat dilihat pada gambar 4.

Gambar 4. Hasil Pemetaan dengan Importance-Performance Analysis

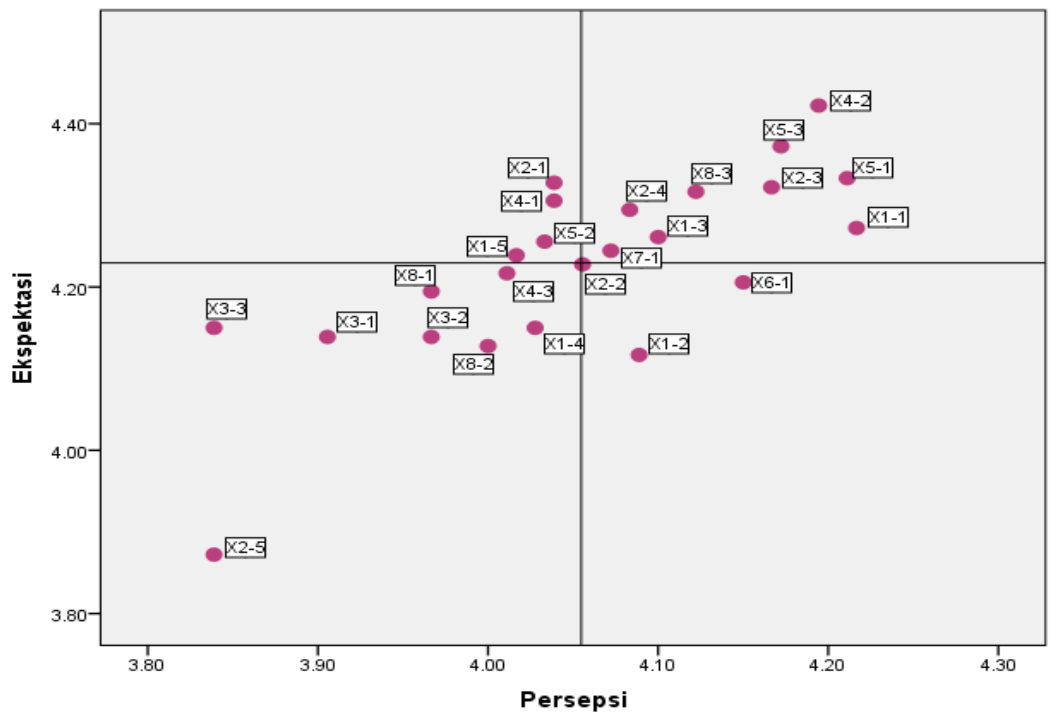

Dari diagram kartesius tersebut terlihat pada kuadran 1 ada empat atribut yang perlu ditingkatkan dengan prioritas utama yaitu X1-5, X2-1, X4-1, X5-2. Pada kuadran 2 terdapat sepuluh atribut sebagai kekuatan serta pilar dari perusahaan dan bisa menjadi kebanggaan, yaitu X1-1, X1-3, X2-2, X2-3, X2-4, X42, X5-1, X5-3, X7-1, X8-3. Pada kuadran 3 terdapat delapan atribut sebagai prioritas rendah sebab dianggap kurang atau tidak penting oleh pelanggan dan tidak 
menimbulkan ancaman besar bagi perusahaan, yaitu X1-4, X2-5, X3-1, X3-2, X3-3, X4-3, X8-1, X8-2. Pada kuadran 4 terdapat dua atribut sebagai atribut-atribut layanan yang dianggap kurang penting tetapi pelanggan memperoleh kepuasan yang berlebih dari atribut ini, yaitu X1-2 dan X6-1.

\section{Analisis dengan Model Kano}

Proses klasifikasi atribut layanan website pada online travel agent dengan menggunakan model Kano pada dasarnya untuk mengkategorikan atribut dari pelayanan jasa yang telah diberikan berdasarkan pada seberapa jauh atribut-atribut tersebut mampu memuaskan kebutuhan pelanggan sehingga kriteria pelayanan yang mempunyai pengaruh paling besar terhadap kepuasan pelanggan dapat diidentifikasi. Lampiran 3 menunjukkan hasil kategorisasi model Kano. Dari 24 atribut layanan pada PT. A sebagai perusahaan jasa online travel agent berbasis $e$ commerce, terdapat 8 atribut yang masuk kategori indifferent (X1-2, X1-3, X1-4, X2-2, X2-4, X2-5, X6$1, \mathrm{X} 8-3)$ yang berarti atribut tersebut dapat diabaikan karena tidak berpengaruh terhadap kepuasan pelanggan. 4 atribut pada kategori must be (X1-1, X2-3, X3-1, X4-2) yang berarti jika atribut ini tidak terpenuhi maka pelanggan akan menjadi tidak puas, tetapi jika atribut-atribut ini terpenuhi juga tidak akan meningkatkan kepuasan pelanggan. Kemudian 12 atribut lainnya masuk kategori one dimensional (X1-5, X2-1, X3-2, X33, X4-1, X4-3, X5-1, X5-2, X5-3, $\mathrm{X} 7-1, \mathrm{X} 8-1, \mathrm{X} 8-2$ ) yang bila tidak terpenuhi akan mempengaruhi tingkat kepuasan pelanggan terhadap layanan, sehingga jika kinerja atribut tinggi menyebabkan tingginya kepuasan pelanggan.

\section{Quality Function Deployment (QFD)}

Setelah melakukan analisis menggunakan metode E-ServQual dan Model Kano, maka dalam upaya memperbaiki, meningkatkan, dan mengembangkan kualitas seluruh atribut dengan menggabungkan hasil E-ServQual dan model Kano kedalam Quality Function Deployment dengan cara menghubungkan atribut-atribut kebutuhan pelanggan dengan respons teknikal perusahaan, sehingga mampu memberikan solusi yang sistematis dalam upaya meningkatkan dan memperbaiki kualitas atribut-atribut tersebut. Berdasarkan hasil penyusunan matriks House of Quality yang dapat dilihat pada Lampiran 4, maka didapatkan prioritas tingkat kepentingan respons teknikal seperti yang ditunjukkan pada

Tabel 3 berikut 
Tabel 3. Urutan Prioritas Tiap Respons Teknikal

\begin{tabular}{|c|c|c|c|}
\hline Respons Teknikal & $\begin{array}{l}\text { Kepentingan } \\
\text { Absolut }\end{array}$ & $\begin{array}{l}\text { Kepentingan } \\
\text { Relatif }(\%)\end{array}$ & $\begin{array}{l}\text { Urutan } \\
\text { Prioritas }\end{array}$ \\
\hline $\begin{array}{l}\text { Rutin memperbaharui isi situs } \\
\text { resmi website travel online }\end{array}$ & 35,60 & 12,00 & 1 \\
\hline $\begin{array}{l}\text { Upgrade teknologi perangkat } \\
\text { lunak untuk web }\end{array}$ & 31,08 & 10,5 & 2 \\
\hline $\begin{array}{l}\text { Mendapatkan sistem sertifikasi } \\
\text { digital }\end{array}$ & 29,88 & 10,1 & 3 \\
\hline $\begin{array}{l}\text { Optimalisasi dan efisiensi database } \\
\text { web }\end{array}$ & 25,80 & 8,70 & 4 \\
\hline $\begin{array}{l}\text { Pengembangan bagian penanganan } \\
\text { klaim bagi pelanggan }\end{array}$ & 25,60 & 8,64 & 5 \\
\hline Customer service tersedia 24 jam & 22,80 & 7,69 & 6 \\
\hline $\begin{array}{l}\text { Memperbanyak media komunikasi } \\
\text { kepada pelanggan }\end{array}$ & 22,24 & 7,5 & 7 \\
\hline $\begin{array}{l}\text { Mencantumkan daftar rincian } \\
\text { produk/ jasa yang dibeli }\end{array}$ & 19,56 & 6,60 & 8 \\
\hline $\begin{array}{l}\text { Pelatihan tentang web security } \\
\text { kepada staf }\end{array}$ & 19,44 & 6,56 & 9 \\
\hline $\begin{array}{l}\text { Merancang ulang/ memperbaiki } \\
\text { user interface dari website }\end{array}$ & 17,64 & 5,95 & 10 \\
\hline $\begin{array}{l}\text { Pengembangan kemampuan } \\
\text { komunikasi customer service }\end{array}$ & 15,84 & 5,34 & 11 \\
\hline $\begin{array}{l}\text { Penambahan atau pelatihan staf } \\
\text { dengan posisi tertentu }\end{array}$ & 8,96 & 3,02 & 12 \\
\hline $\begin{array}{l}\text { Memperbaiki koordinasi dengan } \\
\text { pihak bank }\end{array}$ & 8,16 & 2,75 & 13 \\
\hline $\begin{array}{l}\text { Memperbanyak kerjasama dengan } \\
\text { partner di bidang pariwisata }\end{array}$ & 6,40 & 2,16 & 14 \\
\hline $\begin{array}{l}\text { Rutin memberikan notifikasi } \\
\text { tentang produk/ jasa terbaru }\end{array}$ & 4,08 & 1,38 & 15 \\
\hline $\begin{array}{l}\text { Penambahan stasiun pelayanan } \\
\text { untuk customer service }\end{array}$ & 3,36 & 1,13 & 16 \\
\hline
\end{tabular}

\section{SIMPULAN}

Variabel-variabel bebas yaitu website design, reliability, security, fulfillment, personalization, dan empathy berpengaruh positif terhadap variabel terikat yaitu kepuasan pengguna, dengan tingkat pengaruh terbesar adalah variabel website design dengan nilai koefisien korelasi yang dihasilkan 0,412 . Dengan menggunakan metode $E$ ServQual didapatkan seluruh performa atribut pelayanan secara keseluruhan belum sesuai dengan keinginan pelanggan karena masih didapatkan nilai kesenjangan negatif untuk 24 atribut pelayanan. Setelah melalui perhitungan gap score, dilanjutkan dengan pemetaan kedalam matriks ImportancePerformance Analysis yang menghasilkan 4 atribut jatuh pada kuadran 1 sebagai prioritas utama untuk diperhatikan dan diperbaiki, 10 
atribut pada kuadran 2 sebagai atribut-atribut yang perlu dipertahankan prestasinya, 8 atribut pada kuadran 3 sebagai prioritas rendah, dan 2 atribut pada kuadran 4 golongan yang dianggap kurang penting oleh pelanggan.

12 atribut yang masuk dalam kategori one dimensional serta memperoleh gap score negatif perlu dilakukan strategi berupa peningkatan juga perbaikan kualitas pelayanan, dan 4 atribut pada kategori must be serta memperoleh gap score negatif perlu dilakukan strategi berupa perbaikan secara intensif, sedangkan untuk yang berkategori indifferent dapat diabaikan karena cenderung tidak berpengaruh terhadap kepuasan pengguna. Setelah menerapkan Quality Function Deployment berdasarkan integrasi dari metode $E$ ServQual dan Model Kano didapatkan 5 respons teknikal yang mendapatkan kepentingan relatif terbesar yaitu rutin memperbaharui isi situs resmi website travel online $(12,00 \%)$, upgrade teknologi perangkat lunak untuk web $(10,50 \%)$, mendapatkan sistem sertifikasi digital $(10,10 \%)$, optimalisasi dan efisiensi database web $(8,70 \%)$, dan pengembangan bagian penanganan klaim bagi pelanggan $(8,64 \%)$. 
DAFTAR PUSTAKA

[1] Tjiptono, Fandy. 2001. Strategi Pemasaran Edisi Pertama. Yogyakarta: Andi Ofset.

[2] Sugiyono. 2006. Metode Penelitian Pendidikan, Pendekatan Kuantitatif, Kualitatif, dan R\&D. Bandung: Penerbit Alfabeta.

[3] Umar, H. 2002. Riset Pemasaran dan Perilaku Konsumen. Jakarta: Gramedia Pustaka Utama.

[4] Widjoyo, Iksan Ongko dkk. 2013. "Analisa Pengaruh Kualitas Layanan Terhadap Kepuasan Konsumen Pada Layanan Drive Thru McDonald's Basuki Rahmat di Surabaya". Jurnal Manajemen Pemasaran. 1(1); 1-12.

[5] Ghozali, Imam. 2006. Aplikasi Analisis Multivariat dengan Program SPSS. Semarang: Badan Penerbit Universitas Diponegoro.

[6] Malhotra, N. 2004. Marketing Research. Upper Saddle River: Pearson Prentice Hall. Intl.

[7] Anggraeni, N. M. S. dan Yasa, N. N. K. 2012. "E-Service Quality Terhadap Kepuasan Dan Loyalitas Pelanggan Dalam Pelangganan Internet Banking". Jurnal Keuangan dan Perbankan. 16(2); 293306.

[8] Chase, R. B., dkk. 2006. Operations Management for Competitive Advantage 11th $E d$. New York: McGraw Hill.

[9] Li, Hongxiu dan Suomi, Reima. 2009. "A Proposed Scale for Measuring E-Service Quality". International Journal of $u$ - and
e-Service, Science, and Technology. 2(1); 1-10.

[10]

http://publication.gunadarma.ac.i d/bitstream/123456789/1079/1/1 1107587.pdf (diakses pada 02 November 2016, Pukul 15.45 WIB)

[11] Wong, Meng Seng dkk. 2011. "The Use of ImportancePerformance Analysis (IPA) in Evaluating Japan's Egovernment Services". Journal of Theoretical and Applied Electronic Commerce Research, 17-30.

[12] Tan, K.C. dan T.A. Pawitra. 2001. "Integrating Servqual and Kano's Model into QFD for Service Excellence Development". Managing Service Quality. 11(6); 418430.

[13] Walden, D. 1993. "Special issue on Kano's Methods for Understanding Customer Defined Quality". The Center for Quality of Management Journal. 2(4); 3 -35.

[14] Cohen, L. 1995. Quality Function Deployment: How To Make QFD Work For You. Singapore: Addison-Wesley Publishing Company.

[15] Mulyono, Bayu Hadyanto, dkk. 2007. "Analisis Pengaruh Kualitas Produk Dan Kualitas Layanan Terhadap Kepuasan Konsumen (Studi Kasus Pada Perumahan Puri Mediterania Semarang)". Jurnal Studi Manajemen dan Organisasi. 4(2); 91-100. 
Vol.13(2) : 85-191 Th. 2017

ISSN: 1907-0896 